\title{
An analysis of equity in treatment of hip fractures for older patients with dementia in acute care hospitals: observational study using nationwide hospital claims data in Japan
}

Shinichi Tomioka ${ }^{1 *}$ (D), Megumi Rosenberg ${ }^{2}$, Kiyohide Fushimi ${ }^{3}$ and Shinya Matsuda ${ }^{4}$

\begin{abstract}
Background: Globally, and particularly in countries with rapidly ageing populations like Japan, there are growing concerns over the heavy burden of ill health borne by older people, and the capacity of the health system to ensure their access to quality care. Older people with dementia may face even greater barriers to appropriate care in acute care settings. Yet, studies about the care quality for older patients with dementia in acute care settings are still few. The objective of this study is to assess whether dementia status is associated with poorer treatment by examining the association of a patient's dementia status with the probability of receiving surgery and the waiting time until surgery for a hip fracture in acute care hospitals in Japan.

Methods: All patients with closed hip fracture were extracted from the Diagnosis Procedure Combination (DPC) database between April 2014 and March 2018. After excluding complicated cases, we conducted regressions with multilevel models. We used two outcome measures: (i) whether the patient received a surgery or was treated by watchful waiting; and (ii) number of waiting days until surgery after admission.

Results: Two hundred fourteen thousand six hundred one patients discharged from 1328 hospitals were identified. Among them, 159,173 patients received surgery. Both 80-89 year-olds (OR 0.87; 95\% Cl, 0.84, 0.90) and those 90 years old and above (OR $0.67 ; 95 \% \mathrm{Cl}, 0.65,0.70)$ had significantly lower odds ratios for receiving surgery compared to 65-79 year-olds. Those with severe dementia had a significantly greater likelihood of receiving surgery compared to those without dementia (OR 1.21; $95 \% \mathrm{Cl}, 1.16,1.25)$. Patients aged 90 years old and above had shorter waiting time for surgery (Coef. $-0.06 ; 95 \% \mathrm{Cl},-0.11,-0.01$ ). Mild dementia did not have a statistically significant impact on the number of waiting days until surgery $(P=0.34)$, whereas severe dementia was associated with shorter waiting days (Coef. $-0.08 ; 95 \% \mathrm{Cl},-0.12,-0.03$ ).

(Continued on next page)
\end{abstract}

\footnotetext{
* Correspondence: stomioka@hiroshima-u.ac.jp

'Department of Public Health and Health Policy, Graduate School of

Biomedical \& Health Sciences, Hiroshima University, 1-2-3 Kasumi, Hiroshima

734-0037, Japan

Full list of author information is available at the end of the article
}

(c) The Author(s). 2020 Open Access This article is licensed under a Creative Commons Attribution 4.0 International License, which permits use, sharing, adaptation, distribution and reproduction in any medium or format, as long as you give appropriate credit to the original author(s) and the source, provide a link to the Creative Commons licence, and indicate if changes were made. The images or other third party material in this article are included in the article's Creative Commons licence, unless indicated otherwise in a credit line to the material. If material is not included in the article's Creative Commons licence and your intended use is not permitted by statutory regulation or exceeds the permitted use, you will need to obtain permission directly from the copyright holder. To view a copy of this licence, visit http://creativecommons.org/licenses/by/4.0/ The Creative Commons Public Domain Dedication waiver (http://creativecommons.org/publicdomain/zero/1.0/) applies to the data made available in this article, unless otherwise stated in a credit line to the data. 
(Continued from previous page)

Conclusions: These findings suggest physicians may be taking proactive measures to preserve physical function for those with severe dementia and to avoid prolonged hospitalization although there are no formal guidelines on prioritization for the aged and dementia patients.

Keywords: Dementia, Ageism, Equity, Surgical treatment, Hip fracture, Hospital function

\section{Background}

Global population ageing is progressing rapidly. By 2050, one in six people in the world will be aged 65 years or over [1]. Improved survival beyond the age of 65 is fueling population ageing, putting increased financial pressure on the systems in place to support the older population, including healthcare. Now more than ever, countries need to ensure equity in healthcare with special attention to older people.

Older adults commonly perceive discrimination in healthcare settings due to their age $[2,3]$. These perceptions are supported by empirical research findings of ageism at different levels of the healthcare system including age-biased clinical decision-making regarding diagnostics and treatments [4]. Negative attitudes of healthcare providers toward older patients are more commonly reported in acute health care settings, where targets and quick turnover are encouraged [5]. Studies suggest older people with dementia may face even greater barriers to appropriate care in acute care settings [6, 7].

Japan has the most aged population in the world. There are growing concerns over the heavy burden of ill health borne by older people, and the capacity of the country's health system to ensure their access to quality care. Much attention is given to the increasing prevalence of dementia and its estimated societal cost, as they pose serious threats to the sustainability of the health and social care systems [8]. Yet, studies about the quality of care provided to the growing number of older patients living with dementia are still few $[9,10]$, and even fewer studies have considered the care they receive in acute care settings for medical conditions and co-morbidities other than dementia $[11,12]$.

The present study is one of the first studies in Japan to use hospital claims data to examine the receipt of acute care by older patients with dementia from an equity perspective. The objective of this study is to quantitatively assess whether dementia status is systematically associated with the likelihood of older patients receiving poorer treatment in acute care settings. Specifically, it will examine the association of a patient's dementia status with the probability of receiving surgery and the waiting time until surgery for a hip fracture in acute care hospitals in Japan, controlling for other patient factors and contextual factors.

Hip fractures are a growing public health problem in Japan with the progression of population ageing. The estimated number of new hip fracture patients per year more than tripled from 53,200 new cases in 1987 to 175 , 700 in 2012 [13]. International consensus is that hip fractures among older people should be operated on within $48 \mathrm{~h}$ of hospital admission [14], although research shows that hip fracture surgery within $24 \mathrm{~h}$ could produce considerably better outcomes $[15,16]$. On average across EU countries, more than three quarters $(77 \%)$ of patients aged 65 and over admitted for a hip fracture were operated within 2 days in 2015, with most of them being treated either on the same day of their admission or the next day [14]. This is in accordance with a common guidance in Europe that hip fracture patients should receive surgery on the day of, or the day after, admission [17]. In Japan, similar guidance has not been issued by a national health authority, although the Japanese Orthopaedic Association recommends surgery within a week of admission [18]. Data from Japan show that the mean duration of preoperative hospital stay for hip fractures was 4.5 days, and the mean duration of hospitalization was 36.8 days in 2014. The long waiting time from hospitalization to surgery is reportedly due mainly to difficulties in securing operating rooms $[19,20]$.

Waiting time for surgery is a process indicator of the efficiency or quality of the health system response often used in international reporting [14]. Studies concerned with equity in healthcare focus on the differences in surgery waiting time by patient characteristics or by contextual factors such as urban or rural geography or hospital characteristics [21-23]. Many of them examine differences in waiting time for elective surgery by patient's socioeconomic status. To the authors' knowledge, only one study has been conducted in Japan to date which considered the effect of a patient's dementia status on surgical delay for a hip fracture [20]. The study was conducted using data on 314 patients aged 60 years or above who were treated for hip fractures at one hospital between January 2006 and June 2012 and found no significant effect of dementia on surgical delay when controlling for other clinical and contextual factors. The present study will use a considerably larger database that covers over a thousand acute care hospitals across Japan.

\section{Methods}

\section{Sources of data}

The data were obtained from the Diagnosis Procedure Combination (DPC) database, a national administrative 
database commenced in 2003 with case-mix classification for the use of acute care inpatient reimbursement. Details of the DPC data are provided elsewhere [24, 25]. As of 2018, 1730 acute care hospitals out of 7134 all hospitals are reimbursed through the DPC [26]. Also, $69.2 \%$ of all general hospital beds are included in the DPC reporting system [27, 28].

In this study, we utilized 4 years of cross-sectional data from FF1 (or Yoshiki 1) of the DPC data covering the period of April 2014 to March 2018, which are the Japanese fiscal years of 2014 to 2017. In addition, we utilized detailed nationwide hospital data available from the Institute for Health Economics and Policy (IHEP) website [29] in order to append key hospital characteristics to each patient record.

\section{Study population}

We selected all patients with a closed hip fracture (closed fracture of neck of femur, closed pertrochanteric fracture, and closed subtrochanteric fracture; ICD10 codes S72.00, S72.10 and S72.20, respectively). Although hip fracture is one of the most frequently encountered injuries in daily practice in Japan, because it is neither malignant nor an emergency, treatment varies widely depending on patient characteristics and environmental resources. Recent guidelines and studies recommend early surgical intervention $[15,16,30-32]$.

We analyzed two outcome variables: (i) receipt of surgical operation (coded as 0 for no surgery and 1 for surgery performed) (i.e., not watching for spontaneous recovery), and (ii) number of waiting days until surgery following admission (coded as a continuous variable with a value of 0 assigned if the surgery was performed on the day of admission).

\section{Explanatory variables}

The main explanatory variable of interest was the patient's level of dementia and its impact on their functional ability as measured by the nationally standardized instrument used to assess the needs and eligibility for care under the long-term care insurance system. For the purposes of DPC data entry, the assessment is applied at the time of hospital admission to all patients 65 years old and older. There are six possible assessment outcomes: having no dementia (coded as 0); being on a scale of I to IV ranging from having some dementia but basically functionally independent (I) to requiring constant care due to severe symptoms or behavior and communication difficulties (IV); or having symptoms so severe that specialized medical care is required (coded $\mathrm{M})$. For the present study, these were grouped into three categories: no dementia (coded as 0 ), mild dementia with little or no loss of function (coded as 1, comprising I and II above), and moderate to severe dementia with significant loss of function (coded as 2, comprising III, IV and $\mathrm{M}$ above). Analyses were also adjusted for age group, sex, fracture type (closed fracture of neck of femur, closed pertrochanteric fracture, closed subtrochanteric fracture), comorbidities (Charlson comorbidity index, groups $0-2$ ), coma level, and ambulance use.

These conditions were routinely recorded in the DPC data except Charlson comorbidity index (CCI) which is calculated from patients' comorbidities at the point of admission using Quan's protocol [33]. While other conditions were recorded at the point of admission, fracture type could be modified during the patient's hospital stay. Coma level was categorized into four consciousness depth levels using the Japan Coma Scale (JCS), which is routinely recorded in DPC data. Details of the JCS are described elsewhere [34]. Ambulance use was flagged when patients were transported by ambulance to reach the hospital. Ambulance use was included as a proxy for the level of emergency, which can also affect the probability of and time until surgery.

\section{Exclusions}

We excluded all types of complicated cases from the study population in an attempt to equalize baseline conditions. We excluded patients who died within $24 \mathrm{~h}$ after admission, and those with co-existing severe trauma (e.g., brain bleeding), repeated surgery cases, or clinically complicated fractures which include bilateral, multiple, implant-related fractures or fracture with dislocation. We also excluded patients with multiple admissions within the 4-year study period, multiple surgeries within one admission, and patients who received surgery more than 180 days after admission. In addition, we excluded patients under 65 years old, because the DPC system does not require recording of dementia status for those younger patients. The impact of these exclusions was subsequently assessed by sensitivity analyses.

\section{Statistical models}

For the first analysis of the probability of receiving surgical operation, we employed a multiple logistic regression model to obtain adjusted odds ratios (ORs) and 95\% confidence intervals (CIs) associated with each explanatory variable using the entire study population. Then, a multiple linear regression model was applied to the subset of data on patients who received an surgery to obtain regression coefficients and 95\% confidence intervals associated with each explanatory variable and the number of waiting days until the surgery. The explanatory variables described previously were all set as compositional factors, whereas hospital factors (i.e. city level and hospital function) were set as contextual factors. We built each model in four steps: 1) age and sex only, 2) age, sex and dementia level, 3) age, sex, dementia level and other 
patient clinical factors, and 4) the full model which included hospital and other contextual factors. Macrolevel variance was calculated for each model using multilevel analysis. Details of multilevel analysis including the calculation of macro-level variance are described elsewhere [35]. Sensitivity analyses were also conducted for each of the exclusion criteria. All analyses were conducted using Stata 16.1.

\section{Results}

\section{Sample extraction and characteristics}

From a total of 572,983 patients with a closed hip fracture recorded during the study period (April 2014-March 2018), 554,225 patients were extracted after confirming target disease name with ICD-10 codes. Secondly, clinically complicated cases were excluded, reducing the patient pool to 264,125 . Thirdly, 49,524 patients were excluded due to limitations of missing values and hospital data. As a result, 214,601 patients discharged from 1328 hospitals were identified as the study population. Among them, 159,173 patients from 1170 hospitals received surgery, and thus, were included in the secondary analysis of waiting days until the surgery. The sample extraction process is summarized in Fig. 1.

Table 1 shows the baseline characteristics of the study sample and those who received a surgery. Females accounted for $77.9 \%$ of the total study sample, and the most common age group was $80-89$ years old (49.2\%). The number of those who were not diagnosed with dementia was 111,414 (51.9\%), whereas 58,400 (27.2\%) and 44,787 (20.9\%) were diagnosed with mild and severe levels of dementia, respectively, in the total study sample. For the 159,173 patients who received a surgery, the mean number of waiting days was 3.66 (SD 3.72) days, with a median of 3 days. This indicates a longer waiting time than what is widely recommended in Europe, but is in accordance with relevant guidance in Japan [18].

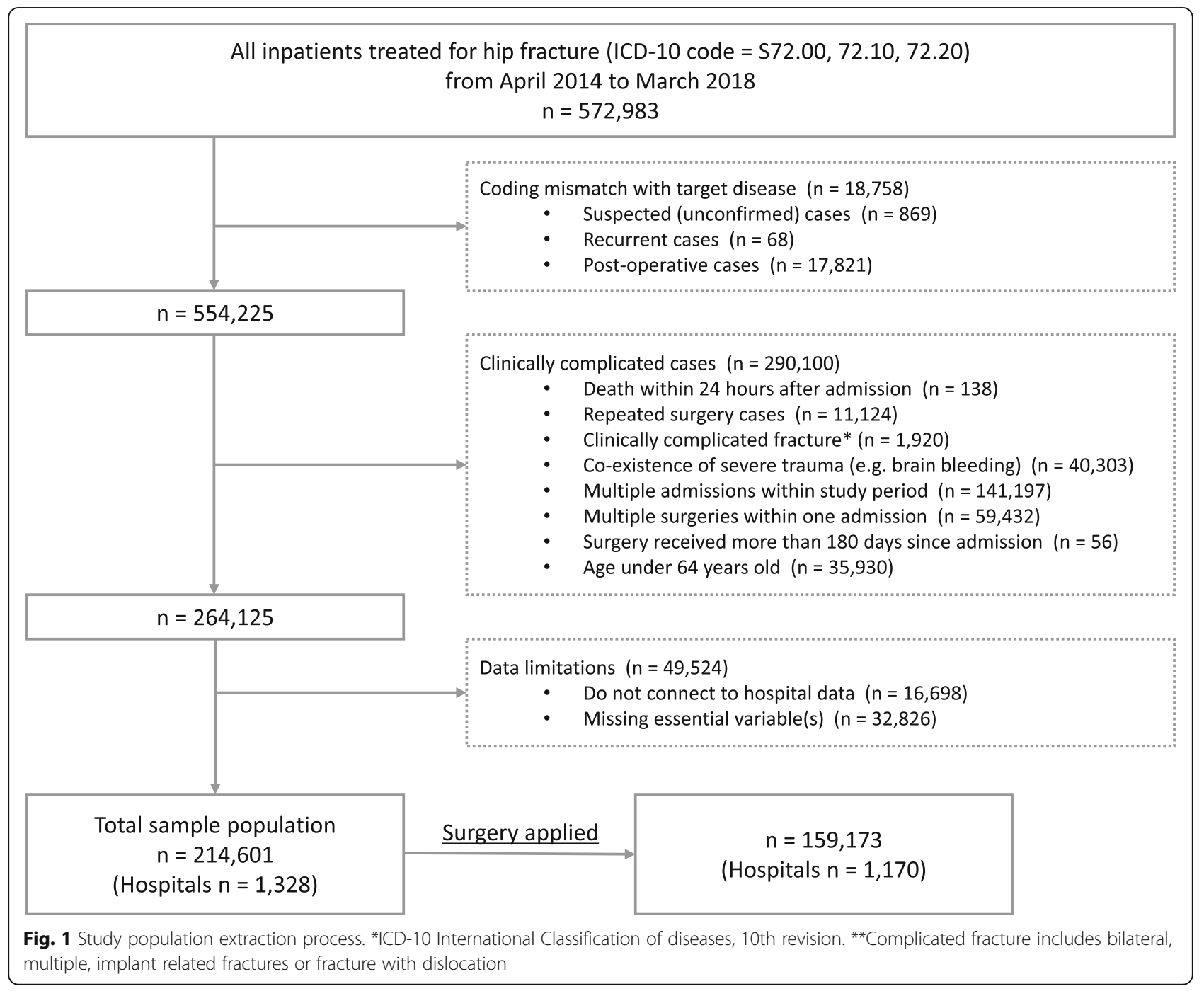


Table 1 Baseline characteristics of the study population, total and surgery applied

\begin{tabular}{|c|c|c|c|c|}
\hline \multirow{3}{*}{ Individual factor } & \multicolumn{2}{|c|}{ Total sample (\%) } & \multicolumn{2}{|c|}{$\underline{\text { Surgery applied (\%) }}$} \\
\hline & \multicolumn{2}{|c|}{$(n=214,601)$} & \multicolumn{2}{|c|}{$(n=159,173)$} \\
\hline & & & & \\
\hline \multicolumn{5}{|l|}{ Sex } \\
\hline Male & 47,456 & $(22.1)$ & 34,904 & $(21.9)$ \\
\hline Female & 167,145 & $(77.9)$ & 124,269 & (78.1) \\
\hline \multicolumn{5}{|l|}{ Age Group } \\
\hline $65-79$ & 57,608 & $(26.8)$ & 44,528 & $(28.0)$ \\
\hline $80-89$ & 105,505 & $(49.2)$ & 78,333 & $(49.2)$ \\
\hline Over 90 & 51,488 & $(24.0)$ & 36,312 & $(22.8)$ \\
\hline \multicolumn{5}{|l|}{ Dementia Level $^{a}$} \\
\hline 0 & 111,414 & $(51.9)$ & 84,424 & $(53.0)$ \\
\hline 1 & 58,400 & $(27.2)$ & 42,187 & $(26.5)$ \\
\hline 2 & 44,787 & $(20.9)$ & 32,562 & $(20.5)$ \\
\hline \multicolumn{5}{|l|}{ Fructure Type } \\
\hline Femoral neck & 115,753 & (53.9) & 88,243 & $(55.4)$ \\
\hline Trochanteric & 95,946 & $(44.7)$ & 69,229 & $(43.5)$ \\
\hline Subtrochanteric & 2900 & $(1.4)$ & 1701 & $(1.1)$ \\
\hline \multicolumn{5}{|l|}{ Charlson Index } \\
\hline 0 & 94,182 & $(43.9)$ & 68,173 & $(42.8)$ \\
\hline 1 & 67,259 & (31.3) & 51,625 & $(32.4)$ \\
\hline$\geq 2$ & 53,160 & $(24.8)$ & 39,375 & $(24.7)$ \\
\hline \multicolumn{5}{|l|}{ Coma Level $^{\mathrm{b}}$} \\
\hline Alert & 183,672 & $(85.6)$ & 136,161 & $(85.5)$ \\
\hline Level 1 & 29,890 & $(13.9)$ & 22,301 & $(14.0)$ \\
\hline Level 2 & 966 & $(0.5)$ & 668 & $(0.4)$ \\
\hline Level 3 & 73 & $(0.03)$ & 43 & $(0.03)$ \\
\hline \multicolumn{5}{|l|}{ Ambulance use } \\
\hline No ambulance use & 103,136 & $(48.1)$ & 68,992 & $(43.3)$ \\
\hline Ambulance use & 111,465 & $(51.9)$ & 90,181 & $(56.7)$ \\
\hline \multicolumn{5}{|l|}{ Hospital factor } \\
\hline \multicolumn{5}{|l|}{ City level ${ }^{c}$} \\
\hline Designated city & 62,667 & $(29.2)$ & 47,388 & $(29.8)$ \\
\hline Population $\geq 150,000$ & 70,862 & (33.0) & 54,353 & $(34.2)$ \\
\hline Population $80,000 \leq, \leq 150,000$ & 39,173 & $(18.3)$ & 29,661 & $(18.6)$ \\
\hline Population $\leq 80,000$ & 41,899 & $(19.5)$ & 27,771 & $(17.5)$ \\
\hline \multicolumn{5}{|l|}{ Hospital function ${ }^{d}$} \\
\hline University \& advanced hospitals & 5288 & $(2.5)$ & 4263 & $(2.7)$ \\
\hline Regional support hospital & 52,802 & (24.6) & 44,825 & $(28.2)$ \\
\hline Over 200 beds hospital & 117,215 & $(54.6)$ & 91,272 & $(57.3)$ \\
\hline Under 200 beds hospital & 39,296 & $(18.3)$ & 18,813 & $(11.8)$ \\
\hline \multicolumn{5}{|l|}{ Length of stay factor } \\
\hline \multicolumn{5}{|l|}{ Discharge to } \\
\hline Home & 58,673 & $(27.3)$ & 32,873 & $(20.7)$ \\
\hline Recovery ward (same hosp.) & 6318 & $(2.9)$ & 3255 & $(2.04)$ \\
\hline
\end{tabular}


Table 1 Baseline characteristics of the study population, total and surgery applied (Continued)

\begin{tabular}{|c|c|c|c|c|}
\hline & \multicolumn{2}{|c|}{ Total sample (\%) } & \multicolumn{2}{|c|}{ Surgery applied (\%) } \\
\hline & \multicolumn{2}{|c|}{$(n=214,601)$} & \multicolumn{2}{|c|}{$(n=159,173)$} \\
\hline Other hospital & 108,323 & $(50.5)$ & 93,681 & $(58.9)$ \\
\hline Long-term care facility & 38,337 & $(17.9)$ & 27,584 & $(17.3)$ \\
\hline Death & 2679 & (1.3) & 1605 & $(1.0)$ \\
\hline Unknown & 264 & $(0.1)$ & 168 & $(0.1)$ \\
\hline
\end{tabular}

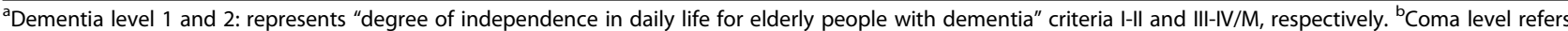
to the Japan Coma Scale (JCS) which has four decisive levels of consciousness. 'Designated city has population over 500,000 and is designated by order of the Cabinet of Japan under Local Autonomy Law. ${ }^{\mathrm{d}}$ Advanced hospitals include 6 national centers for cancer, circulation and global health. Regional support hospital has over 200 beds and meets requirements such as referral rate over $80 \%$ for outpatients

\section{Analysis 1: receipt of surgery}

The results for the probability of receipt of surgery are shown in Table 2. In terms of age, both $80-89$ year-olds (OR 0.87; 95\% CI, 0.84, 0.90) and those 90 years old and above (OR 0.67; 95\% CI, 0.65, 0.70) had significantly lower odds ratios for receiving surgery compared to 6579 year-olds in the full model (model 4). With respect to dementia, in the full model, although patients with mild dementia were no more likely than those without dementia to receive surgery (OR 1.03; 95\% CI, 1.00, 1.06), those with severe dementia had a significantly greater likelihood of receiving surgery compared to those without dementia (OR 1.21; 95\% CI, 1.16, 1.25). Fracture type was also an important predictor of receiving surgery, with lower ORs observed for trochanteric (OR 0.79; 95\% CI, 0.77, 0.81) and subtrochanteric fractures (OR 0.42; 95\% CI, 0.38, 0.46). Patients with deeper coma levels were significantly less likely to receive a surgery (OR 0.56; 95\% CI, 0.31, 1.01).

While a majority of compositional factors affected the probability of an older hip fracture patient receiving a surgery with statistical significance, the impact of contextual factors was rather negligible. In the full model, while city level did not significantly affect the probability of receiving a surgery, hospital function had a rather high impact, where the probability of receiving a surgery was highest in regional support hospitals (OR 15.07; 95\% CI, 11.13, 20.42) followed by university and advanced hospitals (OR 10.90; 95\% CI, 7.05, 16.83) and other types of hospitals with over 200 beds (OR 8.36; 95\% CI, 6.73, 10.40) compared to other types of hospitals with under 200 beds, respectively. Reduction of macro-level variance from model 3 (4.04) to model 4 (2.83) also showed the impact of these contextual factors.

\section{Analysis 2: waiting days for surgery}

The results for waiting time until surgery are shown in Table 3. Patients who were 90 years old and above had shorter waiting time (Coef. -0.06; 95\% CI, - 0.11, - 0.01) compared to those aged 65 to 79 , while the 80-89 yearold group did not $(P=0.10)$. In terms of dementia, similarly to the results for receipt of surgery, mild dementia did not have a statistically significant impact on the number of waiting days until surgery $(P=0.34)$, whereas severe dementia was associated with shorter waiting time (Coef. -0.08 ; 95\% CI, $-0.12,-0.03$ ). Deeper coma levels incrementally lengthened waiting days; coefficients for coma level 2 and 3 were 0.26 (95\% CI, 0.00, 0.51) and 1.18 (95\% CI, 0.19, 2.17), respectively.

Similarly with the results for receipt of surgery, city level was not associated with waiting time until surgery. However, two of the variables for hospital function had statistical significance, which were regional support hospital (Coef. -0.66 ; 95\% CI, $-1.00,-0.31$ ) and other types of hospitals over 200 beds (Coef. $-0.40,95 \%$ CI, -0.66 , -0.14 ). Unlike in the analysis of receiving surgery, macro-level variances between hospitals did not reduce from model 3 (3.22) to model 4 (3.16).

\section{Sensitivity analysis}

Sensitivity analyses were conducted for each of potentially arbitrary exclusion criteria. First, we ran all models for patients with each of clinically complicated case (i.e. death within $24 \mathrm{~h}$ after admission, patients with coexisting severe trauma, repeated surgery cases, clinically complicated fractures, patients with multiple admissions within the 4-year study period, multiple surgeries within one admission). Then, we adjusted for patients waiting days from admission to surgery which was limited 180 days from admission in present study. We adjusted for waiting days from 30 days to 365 days. We confirmed the main results were invariant.

\section{Discussion}

This study found no evidence of unfavorable treatment of patients with dementia for a hip fracture in acute care hospitals in Japan. On the contrary, the findings suggest that patients with severe dementia may be prioritized for surgery resulting in a greater likelihood of them receiving surgery. Furthermore, they may be given a shorter waiting time compared to patients without dementia or with only mild dementia who are otherwise similar in terms of clinical and contextual characteristics. Even patients with mild dementia are treated no differently from patients without dementia. 
Table 2 Multivariate-adjusted odds ratios and 95\% Confidence Intervals for application of surgery

\begin{tabular}{|c|c|c|c|c|c|c|c|c|c|c|c|c|c|c|c|c|}
\hline \multirow[t]{2}{*}{$\boldsymbol{N}=214,601$} & \multicolumn{4}{|c|}{ model 1 (age, sex) } & \multicolumn{4}{|c|}{ model 2 (Dementia level only) } & \multicolumn{4}{|c|}{ model 3 (with clinical factors) } & \multicolumn{4}{|c|}{ model 4 (with hospital factors) } \\
\hline & \multirow[t]{2}{*}{$\overline{\mathrm{OR}}$} & \multicolumn{2}{|c|}{$95 \%$ C.I. } & \multirow[t]{2}{*}{$P$ value } & \multirow[t]{2}{*}{$\overline{\mathrm{OR}}$} & \multicolumn{2}{|c|}{$95 \%$ C.I. } & $P$ value & $\overline{\mathrm{OR}}$ & \multicolumn{2}{|c|}{$95 \%$ C.I. } & $P$ value & $\overline{\mathrm{OR}}$ & \multicolumn{2}{|c|}{ 95\% C.I. } & $P$ value \\
\hline \multicolumn{5}{|l|}{ Compositional factor } & & & & & & & & & & & & \\
\hline \multicolumn{17}{|l|}{ Sex } \\
\hline \multicolumn{17}{|l|}{ Male (reference) } \\
\hline Female & 1.15 & 1.12 & 1.19 & $<0.001$ & & & & & 1.16 & 1.12 & 1.19 & $<0.001$ & 1.16 & 1.12 & 1.19 & $<0.001$ \\
\hline \multicolumn{17}{|l|}{ Age Group } \\
\hline \multicolumn{17}{|l|}{$65-79$ (ref.) } \\
\hline $80-89$ & 0.87 & 0.84 & 0.89 & $<0.001$ & & & & & 0.87 & 0.84 & 0.90 & $<0.001$ & 0.87 & 0.84 & 0.90 & $<0.001$ \\
\hline Over 90 & 0.67 & 0.64 & 0.69 & $<0.001$ & & & & & 0.67 & 0.65 & 0.70 & $<0.001$ & 0.67 & 0.65 & 0.70 & $<0.001$ \\
\hline \multicolumn{17}{|l|}{ Dementia Level $^{a}$} \\
\hline \multicolumn{17}{|l|}{ No dementia (ref.) } \\
\hline Dementia level 1 & & & & & 0.94 & 0.91 & 0.97 & $<0.001$ & 1.03 & 1.00 & 1.06 & 0.08 & 1.03 & 1.00 & 1.06 & 0.06 \\
\hline Dementia level 2 & & & & & 1.06 & 1.02 & 1.09 & $<0.001$ & 1.20 & 1.16 & 1.25 & $<0.001$ & 1.21 & 1.16 & 1.25 & $<0.001$ \\
\hline \multicolumn{17}{|l|}{ Fx. Type } \\
\hline \multicolumn{17}{|l|}{ Femoral neck (ref.) } \\
\hline Trochanteric & & & & & & & & & 0.79 & 0.77 & 0.81 & $<0.001$ & 0.79 & 0.77 & 0.81 & $<0.001$ \\
\hline Subtrochanteric & & & & & & & & & 0.42 & 0.38 & 0.46 & $<0.001$ & 0.42 & 0.38 & 0.46 & $<0.001$ \\
\hline Charlson Index & & & & & & & & & & & & & & & & \\
\hline 0 (ref.) & & & & & & & & & & & & & & & & \\
\hline 1 & & & & & & & & & 1.18 & 1.15 & 1.22 & $<0.001$ & 1.18 & 1.15 & 1.22 & $<0.001$ \\
\hline$\geq 2$ & & & & & & & & & 1.00 & 0.97 & 1.03 & 0.96 & 1.00 & 0.97 & 1.03 & 0.93 \\
\hline Coma Level $^{b}$ & & & & & & & & & & & & & & & & \\
\hline Alert (ref.) & & & & & & & & & & & & & & & & \\
\hline Level 1 & & & & & & & & & 0.94 & 0.91 & 0.98 & 0.01 & 0.94 & 0.90 & 0.98 & 0.00 \\
\hline Level 2 & & & & & & & & & 0.67 & 0.56 & 0.80 & $<0.001$ & 0.67 & 0.56 & 0.80 & $<0.001$ \\
\hline Level 3 & & & & & & & & & 0.55 & 0.31 & 1.00 & 0.05 & 0.56 & 0.31 & 1.01 & 0.05 \\
\hline Ambulance Use & & & & & & & & & & & & & & & & \\
\hline No ambulance us & & & & & & & & & & & & & & & & \\
\hline Ambulance use & & & & & & & & & 1.37 & 1.33 & 1.40 & $<0.001$ & 1.36 & 1.33 & 1.40 & $<0.001$ \\
\hline
\end{tabular}

\section{Contextual factor}

City level ${ }^{c}$

Designated city (ref.)

Pop. $\geq 150,000$

Pop. $80,000 \leq, \leq 150,000$

Pop. $\leq 80,000$

Hosp. function ${ }^{d}$

Under 200 beds hosp.(ref.)

$\begin{array}{llll}1.04 & 0.82 & 1.32 & 0.76 \\ 1.24 & 0.92 & 1.67 & 0.16 \\ 0.97 & 0.74 & 1.26 & 0.80\end{array}$

Over 200 beds hosp.

Regional support hosp.

University \& advanced hosp.

Macro-level variance (S.E.)

between hospitals $(n=1328) \quad 4.18 \quad(0.20)$

$4.20 \quad(0.20)$

$4.04 \quad(0.19)$

$\begin{array}{llll}8.36 & 6.73 & 10.40 & <0.001\end{array}$

$\begin{array}{llll}15.07 & 11.13 & 20.42<0.001\end{array}$

$10.90 \quad 7.05 \quad 16.83<0.001$

aDementia level 1 and 2: represents "degree of independence in daily life for elderly people with dementia" criteria I-II and III-IV/M, respectively. ${ }^{\mathrm{b}} \mathrm{Coma}$ level refers to the Japan Coma Scale (JCS) which has four decisive levels of consciousness. 'Designated city has population over 500,000 and is designated by order of the Cabinet of Japan under Local Autonomy Law. ${ }^{\mathrm{d} A d v a n c e d}$ hospitals include 6 national centers for cancer, circulation and global health. Regional support hospital has over 200 beds and meets requirements such as referral rate over $80 \%$ for outpatients 
Table 3 Multivariate-adjusted coefficients and 95\% Cls for waiting days for surgery with macro-level variance

\begin{tabular}{|c|c|c|c|c|c|c|c|c|c|c|c|c|c|c|c|c|}
\hline \multirow[t]{2}{*}{$\boldsymbol{N}=159,173$} & \multicolumn{4}{|c|}{ model 1 (age, sex) } & \multicolumn{4}{|c|}{$\begin{array}{l}\text { model } 2 \text { (Dementia level } \\
\text { only) }\end{array}$} & \multicolumn{4}{|c|}{ model 3 (with clinical factors) } & \multicolumn{4}{|c|}{$\begin{array}{l}\text { model } 4 \text { (with hospital } \\
\text { factors) }\end{array}$} \\
\hline & coef. & \multicolumn{2}{|c|}{ 95\% C.I. } & $P$ value & coef. & \multicolumn{2}{|c|}{ 95\% C.I. } & $\begin{array}{l}P \\
\text { value }\end{array}$ & coef. & \multicolumn{2}{|c|}{ 95\% C.I. } & $P$ value & coef. & \multicolumn{2}{|c|}{ 95\% C.I. } & $\begin{array}{l}P \\
\text { value }\end{array}$ \\
\hline \multicolumn{17}{|l|}{ Compositional factor } \\
\hline \multicolumn{17}{|l|}{ Sex } \\
\hline \multicolumn{17}{|l|}{ Male (reference) } \\
\hline Female & -0.34 & -0.38 & -0.30 & $<0.001$ & & & & & -0.26 & $\overline{0} \cdot 30$ & -0.22 & $<0.001$ & $-\overline{0.26}$ & $\overline{0} .30$ & $\overline{0}-22$ & $\begin{array}{l}< \\
0.001\end{array}$ \\
\hline \multicolumn{17}{|l|}{ Age Group } \\
\hline \multicolumn{17}{|l|}{ 65-79 (ref.) } \\
\hline $80-89$ & -0.05 & -0.09 & -0.01 & 0.01 & & & & & 0.03 & -0.01 & 0.07 & 0.10 & 0.03 & -0.01 & 0.07 & 0.10 \\
\hline Over 90 & -0.23 & -0.28 & -0.19 & $<0.001$ & & & & & -0.06 & -0.11 & -0.01 & 0.02 & $\overline{-} 0.06$ & -0.11 & $\overline{-} 0.01$ & 0.02 \\
\hline \multicolumn{17}{|l|}{ Dementia Level $^{a}$} \\
\hline \multicolumn{17}{|l|}{ No dementia (ref.) } \\
\hline Dementia level 1 & & & & & 0.02 & -0.02 & 0.06 & 0.28 & 0.02 & -0.02 & 0.06 & 0.34 & 0.02 & -0.02 & 0.06 & 0.34 \\
\hline Dementia level 2 & & & & & -0.06 & $\begin{array}{l}- \\
0.10\end{array}$ & -0.01 & 0.01 & -0.08 & $-\overline{0}$ & -0.03 & 0.002 & -0.08 & $\begin{array}{l}- \\
0.12\end{array}$ & -0.03 & 0.002 \\
\hline \multicolumn{17}{|l|}{ Fx. Type } \\
\hline \multicolumn{17}{|l|}{ Femoral neck (ref.) } \\
\hline Trochanteric & & & & & & & & & -0.72 & -0.75 & -0.68 & $<0.001$ & -0.72 & $-\overline{0}$ & $-\overline{0}$ & $\begin{array}{l}< \\
0.001\end{array}$ \\
\hline Subtrochanteric & & & & & & & & & -0.56 & $\overline{-}-72$ & -0.40 & $<0.001$ & $-\overline{0.56}$ & $\overline{0} .72$ & $\overline{0} .40$ & $\begin{array}{l}< \\
0.001\end{array}$ \\
\hline \multicolumn{17}{|l|}{ Charlson Index } \\
\hline \multicolumn{17}{|l|}{0 (ref.) } \\
\hline 1 & & & & & & & & & 0.39 & 0.35 & 0.43 & $<0.001$ & 0.39 & 0.35 & 0.43 & $\begin{array}{l}< \\
0.001\end{array}$ \\
\hline$\geq 2$ & & & & & & & & & 0.72 & 0.68 & 0.77 & $<0.001$ & 0.72 & 0.68 & 0.77 & 0.93 \\
\hline \multicolumn{17}{|l|}{ Coma Level $^{b}$} \\
\hline \multicolumn{17}{|l|}{ Alert (ref.) } \\
\hline Level 1 & & & & & & & & & 0.06 & 0.00 & 0.11 & 0.04 & 0.06 & 0.00 & 0.11 & 0.04 \\
\hline Level 2 & & & & & & & & & 0.26 & 0.00 & 0.51 & 0.05 & 0.26 & 0.00 & 0.51 & 0.05 \\
\hline Level 3 & & & & & & & & & 1.18 & 0.19 & 2.17 & 0.02 & 1.18 & 0.19 & 2.17 & 0.02 \\
\hline \multicolumn{17}{|l|}{ Ambulance Use } \\
\hline \multicolumn{17}{|l|}{$\begin{array}{l}\text { No ambulance use } \\
\text { (ref.) }\end{array}$} \\
\hline Ambulance use & & & & & & & & & 0.16 & 0.12 & 0.19 & $<0.001$ & 0.16 & 0.12 & 0.19 & $\begin{array}{l}< \\
0.001\end{array}$ \\
\hline
\end{tabular}

\section{Contextual factor}

City level ${ }^{\complement}$

Designated city (ref.)

Pop. $\geq 150,000$

$\begin{array}{llll}0.07 & -0.21 & 0.34 & 0.62\end{array}$

Pop. $80,000 \leq, \leq 150,000$

$\begin{array}{llll}-0.24 & -0.58 & 0.10 & 0.16\end{array}$

Pop. $\leq 80,000$

Hosp. function ${ }^{d}$

Under 200 beds hosp.(ref.)

Over 200 beds hosp. 
Table 3 Multivariate-adjusted coefficients and 95\% Cls for waiting days for surgery with macro-level variance (Continued)

\begin{tabular}{|c|c|c|c|c|c|c|c|c|c|c|c|c|c|}
\hline \multirow[t]{2}{*}{$\boldsymbol{N}=159,173$} & \multicolumn{3}{|c|}{ model 1 (age, sex) } & \multicolumn{3}{|c|}{$\begin{array}{l}\text { model } 2 \text { (Dementia level } \\
\text { only) }\end{array}$} & \multicolumn{3}{|c|}{ model 3 (with clinical factors) } & \multicolumn{4}{|c|}{$\begin{array}{l}\text { model } 4 \text { (with hospital } \\
\text { factors) }\end{array}$} \\
\hline & coef. & 95\% C.I. & $P$ value & coef. & 95\% C.I. & $\begin{array}{l}P \\
\text { value }\end{array}$ & coef. & 95\% C.I. & $P$ value & coef. & $95 \%$ C & & $\begin{array}{l}P \\
\text { value }\end{array}$ \\
\hline $\begin{array}{l}\text { Regional support } \\
\text { hosp. }\end{array}$ & & & & & & & & & & -0.66 & -1.00 & -0.31 & $\begin{array}{l}< \\
0.001\end{array}$ \\
\hline University \& advan & hosp. & & & & & & & & & -0.01 & -0.50 & 0.47 & 0.96 \\
\hline \multicolumn{14}{|c|}{ Macro-level variance (S.E.) } \\
\hline $\begin{array}{l}\text { between hospitals }(n= \\
\text { 1170) }\end{array}$ & 3.24 & $(0.15)$ & & 3.24 & $(0.15)$ & & 3.22 & $(0.15)$ & & 3.16 & $(0.15)$ & & \\
\hline
\end{tabular}

${ }^{\mathrm{a}}$ Dementia level 1 and 2: represents "degree of independence in daily life for elderly people with dementia" criteria I-II and III-IV/M, respectively. ${ }^{\mathrm{b} C o m a}$ level refers to the Japan Coma Scale (JCS) which has four decisive levels of consciousness. 'Designated city has population over 500,000 and is designated by order of the Cabinet of Japan under Local Autonomy Law. ${ }^{\mathrm{d}}$ Advanced hospitals include 6 national centers for cancer, circulation and global health. Regional support hospital has over 200 beds and meets requirements such as referral rate over $80 \%$ for outpatients

With regard to age, the study found that very old patients in their $80 \mathrm{~s}$ and $90 \mathrm{~s}$ are less likely to receive surgery compared to otherwise similar patients who are between the ages of 65 and 79. This result is concerning given that our analysis controlled for comorbidities and functional level. In other words, the observed difference cannot be explained by the possibility that the non-receipt of surgery among the older-old patients was clinically warranted, and thus ethical, due to contraindications or lower levels of functioning. However, for those who did receive surgery, the very old patients tend to have a shorter waiting time compared to the younger-old patients.

These findings suggest that although there are no formal guidelines on patient prioritization, physicians may be taking proactive measures to preserve physical function through surgery for those who are younger and for those with severe dementia. Once the decision to perform surgery is made, then it appears older patients and those with severe dementia are prioritized to avoid prolonged hospitalization for these patients for whom the consequences are likely to be negative. One study from Germany suggests conducting preoperative cognitive assessment (e.g. Mini Mental State Examination; MMSE) for very old patients arguing cognitive impairment is an important prognostic factor for the development of perioperative complications and the duration of the hospital stay [36]. In line with this suggestion, our findings indicate that physicians in Japan knowingly or unknowingly prioritize patients based on their cognitive function thereby helping to avoid undesirable outcomes.

However, the dataset we analyzed limits our understanding of the true causes of the observed patterns of treatment. We would like to think that the basis for the expedited surgery of patients with severe dementia and those who are very old is clinical benefit to the patient. However, it is also possible that hospitals are prioritizing and discharging these patients with complex needs who tend to have prolonged hospital stays, which can reduce turnover of hospital beds and reduce hospital revenue under prospective payment system. In fact, additional analysis from our study showed that the patients with dementia also had shorter lengths of hospital stay following surgery compared to patients with no dementia (Table 4). Qualitative research of the clinicians making these decisions would be informative. Whether the true driving force of this pattern is perceived benefit to the patient or financial incentive for the hospital, or both, the result for the patients with severe dementia and very old patients is that they have shorter waiting times until surgery, which in general is a good outcome. As these patients will require longer periods of recuperation and rehabilitation following discharge, early discharge should be followed by a supported discharge [5].

This study also found that contextual factors, and especially the type or function of the hospital in which the patient received care had significant impact on the probability of the patient receiving surgery for their hip fracture and on their waiting time until surgery, above and beyond the effects of patient characteristics. The positive finding is that patients are not simply disadvantaged by their rural residence. Given that financial barriers to healthcare are minimized in Japan by the national health insurance system, geography, or rural residence, is one of the major concerns related to equity in healthcare. This study found that patients with comparable individual characteristics living in remote areas are just as likely to receive surgery as those living in urban areas without delay as long as they can seek care in high-functioning hospitals. Additional analysis showed a similar pattern in the length of hospital stay in which rural residence had no impact but the hospital's functional level made a significant difference in the patient's duration of hospitalization (Table 5).

\section{Limitations}

The study population only included those patients experiencing hip fractures who received treatment in an acute care hospital which reports to the DPC data system. It did not include those patients who were admitted 
Table 4 Multivariate-adjusted coefficients and 95\% Cls for length of hospital stay with macro-level variance

\begin{tabular}{|c|c|c|c|c|c|c|c|c|c|c|c|c|}
\hline \multirow[t]{2}{*}{$\boldsymbol{N}=214,601$} & \multicolumn{4}{|c|}{ model 1 (all patients, $\boldsymbol{N}=214,601$ ) } & \multicolumn{4}{|c|}{ model 2 (surgery only, $\boldsymbol{N}=159,173$ ) } & \multicolumn{4}{|c|}{ model 3 (non-surgery only, $\boldsymbol{N}=55,428$ ) } \\
\hline & \multirow[t]{2}{*}{ coef. } & \multicolumn{2}{|c|}{ 95\% C.I. } & \multirow[t]{2}{*}{$P$ value } & \multirow[t]{2}{*}{ coef. } & \multicolumn{2}{|c|}{$95 \%$ C.I. } & \multirow[t]{2}{*}{$P$ value } & \multirow[t]{2}{*}{ coef. } & \multicolumn{2}{|l|}{ 95\% C.I. } & \multirow[t]{2}{*}{$P$ value } \\
\hline \multicolumn{7}{|l|}{ Compositional factor } & & & & & & \\
\hline \multicolumn{13}{|l|}{ Sex } \\
\hline \multicolumn{13}{|l|}{ Male (reference) } \\
\hline Female & -0.23 & -0.44 & -0.02 & 0.04 & -0.60 & -0.77 & -0.44 & $<0.001$ & 0.31 & -0.34 & 0.96 & 0.35 \\
\hline \multicolumn{13}{|l|}{ Age Group } \\
\hline \multicolumn{13}{|l|}{ 65-79 (ref.) } \\
\hline $80-89$ & 1.52 & 1.31 & 1.74 & $<0.001$ & 1.16 & 1.00 & 1.33 & $<0.001$ & 2.17 & 1.49 & 2.86 & $<0.001$ \\
\hline Over 90 & 0.85 & 0.58 & 1.11 & $<0.001$ & 0.92 & 0.72 & 1.13 & $<0.001$ & 1.32 & 0.52 & 2.12 & $<0.001$ \\
\hline \multicolumn{13}{|l|}{ Dementia Level $^{a}$} \\
\hline \multicolumn{13}{|l|}{ No dementia (ref.) } \\
\hline Dementia level 1 & 0.67 & 0.44 & 0.89 & $<0.001$ & 0.21 & 0.04 & 0.39 & 0.02 & 1.96 & 1.28 & 2.63 & $<0.001$ \\
\hline Dementia level 2 & -1.70 & -1.96 & -1.44 & $<0.001$ & -1.50 & -1.70 & -1.30 & $<0.001$ & -0.56 & -1.34 & 0.22 & 0.16 \\
\hline \multicolumn{13}{|l|}{ Fx. Type } \\
\hline \multicolumn{13}{|l|}{ Femoral neck (ref.) } \\
\hline Trochanteric & 0.24 & 0.06 & 0.42 & 0.01 & -0.56 & -0.70 & -0.42 & $<0.001$ & 2.38 & 1.84 & 2.93 & $<0.001$ \\
\hline Subtrochanteric & 3.57 & 2.82 & 4.32 & $<0.001$ & 3.00 & 2.35 & 3.66 & $<0.001$ & 5.68 & 3.84 & 7.53 & $<0.001$ \\
\hline \multicolumn{13}{|l|}{ Charlson Index } \\
\hline \multicolumn{13}{|l|}{0 (ref.) } \\
\hline 1 & 1.03 & 0.82 & 1.24 & $<0.001$ & 0.97 & 0.81 & 1.13 & $<0.001$ & 1.39 & 0.73 & 2.06 & $<0.001$ \\
\hline$\geq 2$ & 2.32 & 2.09 & 2.55 & $<0.001$ & 2.46 & 2.28 & 2.64 & $<0.001$ & 2.55 & 1.84 & 3.26 & $<0.001$ \\
\hline \multicolumn{13}{|l|}{ Coma Level $^{\mathrm{b}}$} \\
\hline \multicolumn{13}{|l|}{ Alert (ref.) } \\
\hline Level 1 & -0.94 & -1.23 & -0.66 & $<0.001$ & -0.36 & -0.57 & -0.14 & $<0.001$ & -1.43 & -2.31 & -0.54 & $<0.001$ \\
\hline Level 2 & -0.42 & -1.71 & 0.88 & 0.53 & 0.22 & -0.82 & 1.25 & 0.68 & 0.21 & -3.45 & 3.86 & 0.91 \\
\hline Level 3 & -3.14 & -7.81 & 1.53 & 0.19 & 0.72 & -3.31 & 4.76 & 0.73 & -8.37 & -19.80 & 3.06 & 0.15 \\
\hline \multicolumn{13}{|l|}{ Ambulance Use } \\
\hline \multicolumn{13}{|c|}{ No ambulance use (ref.) } \\
\hline Ambulance use & 1.05 & 0.87 & 1.24 & $<0.001$ & 1.94 & 1.80 & 2.08 & $<0.001$ & -1.47 & -2.10 & -0.84 & $<0.001$ \\
\hline
\end{tabular}

\section{Contextual factor}

City level ${ }^{c}$

Designated city (ref.)

Pop. $\geq 150,000$

Pop. $80,000 \leq, \leq 150,000$

Pop. $\leq 80,000$

$\begin{array}{llll}-0.02 & -1.58 & 1.53 & 0.98 \\ 0.25 & -1.68 & 2.19 & 0.80 \\ 1.51 & -0.19 & 3.21 & 0.08\end{array}$

-2.53
-1.96
-0.15

$-3.78$

$-1.27<0$.

$<0.001 \quad 0.95$

$\begin{array}{lll}-1.00 & 2.90 & 0.34 \\ -1.72 & 3.08 & 0.58 \\ -0.25 & 3.96 & 0.09\end{array}$

Hosp. function ${ }^{\text {d }}$

Under 200 beds hosp.(ref.)

Over 200 beds hosp.

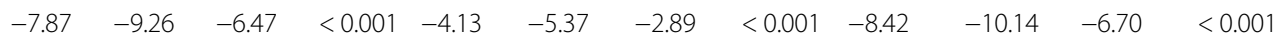

Regional support hosp.

$\begin{array}{lllllll}-12.04 & -13.98 & -10.09 & <0.001 & -9.02 & -10.68 & -7.35\end{array}$

University \& advanced hosp.

$\begin{array}{lllllll}-15.69 & -18.50 & -12.87 & <0.001 & -10.41 & -12.75 & -8.08\end{array}$

$<0.001-12.61-15.01 \quad-10.22 \quad<0.001$

Discharge to

Home (ref.)

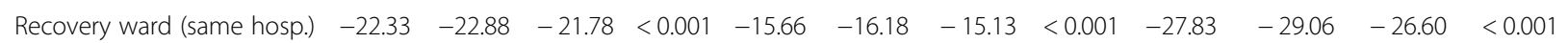

Other hospital

$\begin{array}{llllllllllll}-5.95 & -6.19 & -5.71 & <0.001 & -2.60 & -2.79 & -2.40 & <0.001 & -15.82 & -16.60 & -15.04 & <0.001\end{array}$ 
Table 4 Multivariate-adjusted coefficients and 95\% Cls for length of hospital stay with macro-level variance (Continued)

\begin{tabular}{|c|c|c|c|c|c|c|c|c|c|c|c|c|}
\hline \multirow{3}{*}{$\begin{aligned} \boldsymbol{N}=214,601 \\
\\
\text { Long-term care facility }\end{aligned}$} & \multicolumn{4}{|c|}{ model 1 (all patients, $\boldsymbol{N}=214,601$ ) } & \multicolumn{4}{|c|}{ model 2 (surgery only, $\boldsymbol{N}=159,173$ ) } & \multicolumn{4}{|c|}{ model 3 (non-surgery only, $\boldsymbol{N}=55,428$ ) } \\
\hline & \multirow{2}{*}{$\begin{array}{l}\text { coef. } \\
-5.95\end{array}$} & \multicolumn{2}{|c|}{ 95\% C.I. } & \multirow{2}{*}{$\begin{array}{l}P \text { value } \\
<0.001\end{array}$} & \multirow{2}{*}{$\begin{array}{l}\text { coef. } \\
-5.05\end{array}$} & \multicolumn{2}{|c|}{$95 \%$ C.I. } & \multirow{2}{*}{$\begin{array}{l}P \text { value } \\
<0.001\end{array}$} & \multirow{2}{*}{$\begin{array}{l}\text { coef. } \\
-4.79\end{array}$} & \multicolumn{2}{|c|}{$95 \%$ C.I. } & \multirow{2}{*}{$\begin{array}{l}P \text { value } \\
<0.001\end{array}$} \\
\hline & & -6.24 & -5.66 & & & -5.29 & -4.81 & & & -5.56 & -4.01 & \\
\hline Death & 1.46 & 0.66 & 2.26 & $<0.001$ & -1.93 & -2.62 & -1.25 & $<0.001$ & 8.47 & 6.48 & 10.46 & $<0.001$ \\
\hline Unknown & -2.75 & -5.25 & -0.24 & 0.03 & -1.04 & -3.13 & 1.06 & 0.33 & -4.30 & -10.74 & 2.14 & 0.19 \\
\hline \multicolumn{13}{|l|}{ Macro-level variance (S.E.) } \\
\hline between hospitals & 116.1 & $(5.30)$ & & & 75.3 & $(3.70)$ & & & 136.8 & $(7.27)$ & & \\
\hline
\end{tabular}

${ }^{\mathrm{a}}$ Dementia level 1 and 2: represents "degree of independence in daily life for elderly people with dementia" criteria I-II and III-IV/M, respectively. ${ }^{\mathrm{b}} \mathrm{Coma}$ level refers to the Japan Coma Scale (JCS) which has four decisive levels of consciousness. 'Designated city has population over 500,000 and is designated by order of the Cabinet of Japan under Local Autonomy Law. ${ }^{d}$ Advanced hospitals include 6 national centers for cancer, circulation and global health. Regional support hospital has over 200 beds and meets requirements such as referral rate over $80 \%$ for outpatients

to a non-DPC-reporting hospital beds, which is $30.8 \%$ of all general hospital beds as of 2018, or who never received care in an acute care hospital. Thus, the generalizability of our findings is limited. In order to consider equity in access to care and treatment for hip fractures more broadly, we would need to examine the denominator of all older patients experiencing hip fractures in the community and take into factors such as physical access to an acute care hospital.

\section{Conclusion}

We found hip fracture patients with severe dementia received surgery with a greater likelihood and with a shorter waiting time compared to patients without dementia or with only mild dementia. With regard to age, very old patients in their 80s and 90s are less likely to receive surgery compared to patients between the ages of 65 and 79. For those who did receive surgery, the very old patients tend to have a shorter waiting time. These findings suggest physicians providing acute care for hip fractures in hospitals in Japan may be taking proactive measures to preserve patient's physical function and to avoid prolonged hospitalization based on their age or dementia level in the absence of formal guidelines on patient prioritization. In terms of contextual factors, rural residence in itself was not a disadvantage for these patients seeking care in acute care hospitals; rather, the functional level of the hospital in which they sought care was more likely to affect their likelihood of receiving surgery and the waiting time until surgery. Further study is required to elucidate the extent to which the observed treatment pattern serves the interests of the patient, the healthcare workers, and hospital business administration.

\section{Appendix}

Table 5 Relevant ICD10 codes

\begin{tabular}{lll}
\hline ICD10 code & Disease name & Variable name \\
\hline S72.00 & Closed fracture of neck of femur & Femoral neck (ref.) \\
S72.10 & Closed pertrochanteric fracture & Trochanteric \\
S72.20 & Closed subtrochanteric fracture & Subtrochanteric \\
\hline
\end{tabular}

\section{Abbreviations}

CCl: Charlson Comorbidity Index; DPC: Diagnosis Procedure Combination; JCS: Japan Coma Scale

\section{Acknowledgements}

The views expressed in this article are solely of the authors and do not necessarily represent the official policy or position of the World Health Organization.

The computing software Stata 16.1 is a product of StataCorp LLC and purchased by the authors. All the other instruments such as Charlson Comorbidity Index or Japan Coma Scale are not under license.

\section{Authors' contributions}

ST, MR conducted the study in their respective sites; ST acquired, cleaned and analyzed the data; MR conducted past literature review; ST and MR prepared the first draft of the manuscript; KF and SM prepared the dataset; All authors commented on drafts, read and approved the final manuscript.

\section{Funding}

This study was supported by the World Health Organization Centre for Health Development (WHO Kobe Centre - WKC: K18003).

\section{Availability of data and materials}

The DPC dataset analyzed during the current study are not publicly available due to possible identification of personal information but are available from the corresponding author on reasonable request. Hospital data can be acquired from the IHEP website. https://www.ihep.jp/business/other/

\section{Ethics approval and consent to participate}

Administrative permissions were required to access the data used in this study. The permission was granted by the DPC Research Institute.

\section{Consent for publication}

Not applicable.

\section{Competing interests}

The authors declare that they have no competing interests.

\section{Author details}

${ }^{1}$ Department of Public Health and Health Policy, Graduate School of Biomedical \& Health Sciences, Hiroshima University, 1-2-3 Kasumi, Hiroshima 734-0037, Japan. ${ }^{2}$ World Health Organization Centre for Health Development (WHO Kobe Centre), I.H.D. Centre Building 9th Floor, 1-5-1

Wakinohama-Kaigandori, Chuo-ku, Kobe 651-0073, Japan. ${ }^{3}$ Department of Health Policy and Informatics, Graduate School of Medicine, Tokyo Medical and Dental University, 1-5-45 Yushima, Bunkyo-ku, Tokyo 113-8510, Japan. ${ }^{4}$ Department of Preventive Medicine and Community Health, University of Occupational and Environmental Health, 1-1 Iseigaoka, Yahatanishi-ku, Kitakyushu 807-8555, Japan. 
Received: 4 June 2020 Accepted: 26 August 2020

Published online: 04 September 2020

\section{References}

1. United Nations Department of Economic and Social Affairs Population Division. World population ageing 2019: highlights. New York: United Nations; 2019.

2. Braga LS, Caiaffa WT, Ceolin APR, de Andrade FB, Lima-Costa MF. Perceived discrimination among older adults living in urban and rural areas in Brazil: a national study (ELSI-Brazil). BMC Geriatr. 2019;19(1):67.

3. Nguyen TT, Vable AM, Glymour MM, Nuru-Jeter A. Trends for reported discrimination in health Care in a National Sample of older adults with chronic conditions. J Gen Intern Med. 2018;33(3):291-7.

4. Wyman MF, Shiovitz-Ezra S, Bengel J. Ageism in the health care system: providers, patients, and systems. In: Ayalon L, Tesch-Römer C, editors. Contemporary perspectives on ageism. Cham: Springer International Publishing; 2018. p. 193-212.

5. Kydd A, Fleming A. Ageism and age discrimination in health care: fact or fiction? A narrative review of the literature. Maturitas. 2015;81(4):432-8

6. Houghton C, Murphy K, Brooker D, Casey D. Healthcare staffs' experiences and perceptions of caring for people with dementia in the acute setting: qualitative evidence synthesis. Int J Nurs Stud. 2016;61:104-16.

7. Reilly JC, Houghton C. The experiences and perceptions of care in acute settings for patients living with dementia: a qualitative evidence synthesis. Int J Nurs Stud. 2019;96:82-90.

8. Sado M, Ninomiya A, Shikimoto R, Ikeda B, Baba T, Yoshimura K, et al. The estimated cost of dementia in Japan, the most aged society in the world. PLoS One. 2018;13(11):e0206508.

9. Nakanishi M, Hirooka K, Morimoto Y, Nishida A. Quality of care for people with dementia and professional caregivers' perspectives regarding palliative care in Japanese community care settings. Int J Geriatr Psychiatry. 2017; 32(12):1342-51.

10. Nakanishi M, Miyamoto Y. Palliative care for advanced dementia in Japan: knowledge and attitudes. Br J Nurs. 2016;25(3):146-55.

11. Nakanishi M, Okumura Y, Ogawa A. Physical restraint to patients with dementia in acute physical care settings: effect of the financial incentive to acute care hospitals. International psychogeriatrics / IPA. 2018;30(7):9911000.

12. Sakata N, Okumura Y, Fushimi K, Nakanishi M, Ogawa A. Dementia and risk of 30-day readmission in older adults after discharge from acute care hospitals. J Am Geriatr Soc. 2018;66(5):871-8.

13. Orimo H, Yaegashi $Y$, Hosoi T, Fukushima $Y$, Onoda T, Hashimoto T, et al. Hip fracture incidence in Japan: estimates of new patients in 2012 and 25year trends. Osteoporos Int. 2016;27(5):1777-84.

14. OECD/European Union. Waiting times for hip fracture surgery. Health at a glance: Europe 2018: State of health in the EU cycle. Paris/Brussels: OECD Publishing/European Union; 2018.

15. Ogawa T, Aoki T, Shirasawa S. Effect of hip fracture surgery within 24 hours on short-term mobility. J Orthop Sci. 2019;24(3):469-73.

16. Pincus D, Ravi B, Wasserstein D, Huang A, Paterson JM, Nathens AB, et al. Association between wait time and 30-day mortality in adults undergoing hip fracture surgery. JAMA. 2017;318(20):1994-2003.

17. National Institute for Health and Care Excellence. NICE Guidance, Hip fracture: management 2011 [updated 10 May 2017. Available from: https:// www.nice.org.uk/guidance/cg124/chapter/Recommendations\#timing-ofsurgery.

18. The Japanese Orthopaedic Association. Japanese guidelines for the treatment of hip fractures in the elderly 2nd edition. Tokyo: Nankodo; 2011.

19. Hagino $\mathrm{H}$, Endo $\mathrm{N}$, Harada A, Iwamoto J, Mashiba T, Mori S, et al. Survey of hip fractures in Japan: recent trends in prevalence and treatment. J Orthop Sci. 2017;22(5):909-14.

20. Hagino T, Ochiai S, Senga S, Watanabe $Y$, Wako M, Ando T, et al. Efficacy of early surgery and causes of surgical delay in patients with hip fracture. J Orthop. 2015;12(3):142-6.

21. Cooper ZN, McGuire A, Jones S, Grand JL. Equity, waiting times, and NHS reforms: retrospective study. BMJ. 2009;339:b3264.

22. Shortt SE, Shaw RA. Equity in Canadian health care: does socioeconomic status affect waiting times for elective surgery? CMAJ. 2003;168(4):413-6.

23. Petrelli A, De Luca G, Landriscina T, Costa G, Gnavi R. Effect of socioeconomic status on surgery waiting times and mortality after hip fractures in Italy. J Healthc Qual. 2018;40(4):209-16.
24. Fushimi $K$, Hashimoto $H$, Imanaka Y, Kuwabara K, Horiguchi $H$, Ishikawa KB, et al. Functional mapping of hospitals by diagnosis-dominant case-mix analysis. BMC Health Serv Res. 2007;7(1):50.

25. Matsuda S, Ishikawa KB, Kuwabara K, Fujimori K, Fushimi K, Hashimoto H. Development and use of the Japanese case-mix system. Eurohealth. 2008; 14(3):25-30

26. Ministry of Health Labor and Welfare J. The transition of DPC hospitals and beds. 2018 .

27. The result report of the survey "Discharge patient survey" related to the impact assessment of DPC 2018 [Internet]. 2018. Available from: https:// www.mhlw.go.jp/stf/shingi2/0000196043_00003.html. [cited May 10, 2020]

28. Medical facility (dynamic) survey 2018 [Internet]. 2018. Available from: https://www.mhlw.go.jp/toukei/saikin/hw/iryosd/18/. [cited May 10, 2020].

29. List of all hospitals covered by public health insurance [Internet]. 2019. Available from: https://www.ihep.jp/business/other/. [cited Oct. 10, 2019].

30. Johansen A, Wakeman R, Boulton C, Plant F, Roberts J, Williams A. National Hip Fracture Database: National Report 2013. Clinical Effectiveness and Evaluation Unit at the Royal College of Physicians 2013.

31. Nyholm AM, Gromov K, Palm H, Brix M, Kallemose T, Troelsen A. Time to surgery is associated with thirty-day and ninety-day mortality after proximal femoral fracture. J Bone Joint Surg. 2015;97(16):1333-9.

32. Moja L, Piatti A, Pecoraro V, Ricci C, Virgili G, Salanti G, et al. Timing Matters in Hip Fracture Surgery: Patients Operated within 48 Hours Have Better Outcomes. A Meta-Analysis and Meta-Regression of over 190,000 Patients. PLOS ONE. 2012;7(10):e46175.

33. Quan H, Li B, Couris CM, Fushimi K, Graham P, Hider P, et al. Updating and validating the Charlson comorbidity index and score for risk adjustment in hospital discharge abstracts using data from 6 countries. Am J Epidemiol. 2011;173(6):676-82.

34. Shigemori M, Abe T, Aruga T, Ogawa T, Okudera H, Ono J, et al. Guidelines for the Management of Severe Head Injury, 2nd EditionGuidelines from the guidelines committee on the Management of Severe Head Injury, the Japan Society of Neurotraumatology. Neurol Med Chir. 2012;52(1):1-30.

35. Goldstein H. Multilevel statistical models: John Wiley \& Sons; 2011.

36. Wobith M, Acikgoz A, Grosser K, Weimann A. Preoperative cognitive function in very old patients : influence on the complication rate and length of hospitalization. Chirurg. 2019;90(11):930-5.

\section{Publisher's Note}

Springer Nature remains neutral with regard to jurisdictional claims in published maps and institutional affiliations.

Ready to submit your research? Choose BMC and benefit from:

- fast, convenient online submission

- thorough peer review by experienced researchers in your field

- rapid publication on acceptance

- support for research data, including large and complex data types

- gold Open Access which fosters wider collaboration and increased citations

- maximum visibility for your research: over $100 \mathrm{M}$ website views per year

At BMC, research is always in progress.

Learn more biomedcentral.com/submissions 